\title{
Avaliação e Categorização de Equívocos em Códigos Produzidos no Ensino Introdutório de Computação
}

\section{Tales Lelo da Aparecida, Rodolfo J. de Azevedo, Ricardo E. Caceffo}

\section{Resumo}

Buscar métodos de reconhecer antecipadamente alunos equivocados e auxiliar no direcionamento é essencial.

Este projeto, associado à pesquisa do Dr. Ricardo Caceffo, ambas supervisionadas pelo Dr. Rodolfo Azevedo, visa criar uma ferramenta de diagnóstico de problemas de compreensão dos alunos para disciplinas introdutórias de computação. Foram estudadas algumas alternativas de assistência à alunos e educadores, onde analisou-se o sistema de submissão e testes automáticos de programas de alunos das disciplinas do Instituto de Computação da Unicamp, inicialmente com intuito de reunir erros recorrentes nos códigos submetidos e depois com intenção de sumarizar dados em gráficos e tabelas que fossem facilmente interpretadas por docentes para acompanhamento dos alunos cursando a disciplina. Isto foi implementado como uma extensão da própria ferramenta de submissão, de modo que permitisse fácil incrementação, possivelmente por parte dos próprios professores.

\section{Palavras-chave:}

Análise, Submissões, Programação

\section{Introdução}

O projeto surgiu como parte da iniciativa de elaborar um concept inventory ${ }^{1}$ para alunos do curso Algoritmos e Programação de Computadores da Unicamp, que introduz conceitos de linguagens de programação. Este trabalho atuaria no histórico de erros em submissões de trabalhos semanais, procurando encontrar enganos comuns entre os alunos, descobrindo novos ou simplesmente retificando aqueles encontrados e reportados na pesquisa do Dr. Caceffo, processo FAPESP 2014/07502-4. Contudo, ao perceber o potencial dos dados existentes no sistema, foram elaborados gráficos e tabelas, assim como um sistema que permite aos professores responsáveis por turmas de computação consultarem. Este sistema foi integrado a ferramenta de submissão e agora permite a análise facilitada, em tempo real, das submissões contra cada caso de teste, ou ainda sua distribuição pelo prazo de submissão.

\section{Resultados e Discussão}

Construído com uma estrutura facilmente incrementável, a extensão gera alguns gráficos e tabelas a partir dos dados extraídos das submissões até o momento para um conjunto selecionado de turmas.

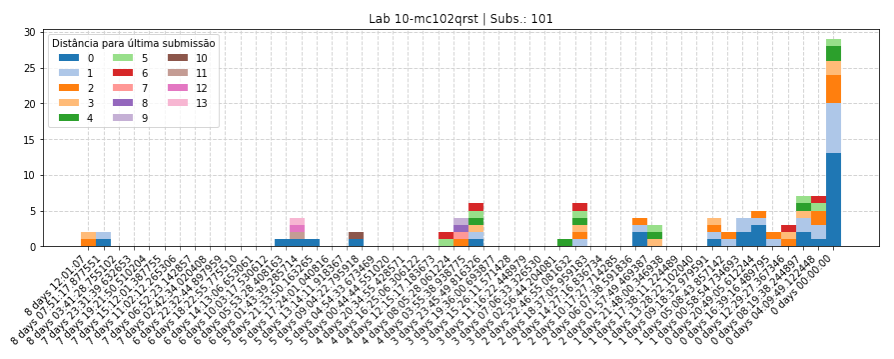

Figura 1. Distribuição de submissões pelo período válido, colorizado de acordo com sua versão.

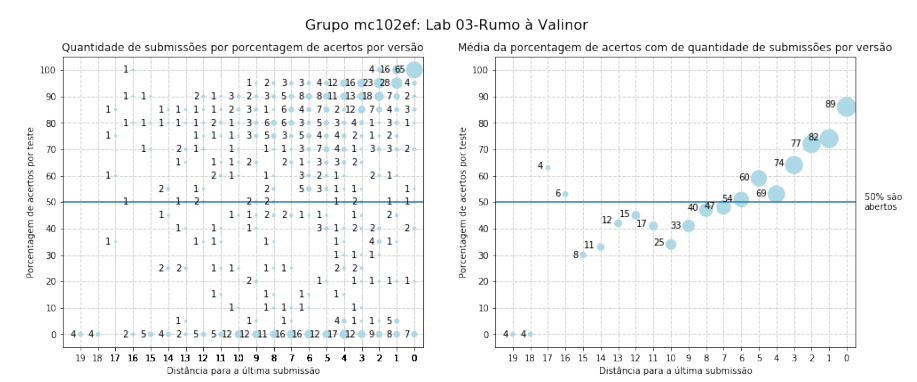

Figura 2. Porcentagem de acertos por versão. O tamanho dos circulos representa a quantidade de submissões. O gráfico a direita mostra a média dada uma versão.

\section{Conclusão}

É previsto que os gráficos e relatórios gerados a partir das submissões no Susy estejam disponíveis para os professores que gerenciem turmas de MC102 no segundo semestre de 2018. Ainda há grande potencial para criar novos modelos de sumarização de dados, mas com a base criada estes poderão ser facilmente adicionados.

\section{Agradecimentos}

Agradeço aos professores Rodolfo Azevedo, Ricardo Caceffo, Islene Garcia, Breno de França e Marco Aurélio Gerosa pelo apoio no desenvolvimento desta pesquisa. Também aos professores Ricardo Anido e Tomasz Kowaltowski pela atenção e suporte que foi dado para uso de suas ferramentas, permitindo sugestões de novas funcionalidades e fornecimento de dados. Agradeço também ao CNPq pelo financiamento prestado.

${ }^{1}$ Caceffo R, Wolfman S, Booth KS, Azevedo R. Developing a computer science concept inventory for introductory programming. InProceedings of the 47th ACM Technical Symposium on Computing Science Education 2016 Feb 17 (pp. 364-369). ACM. 